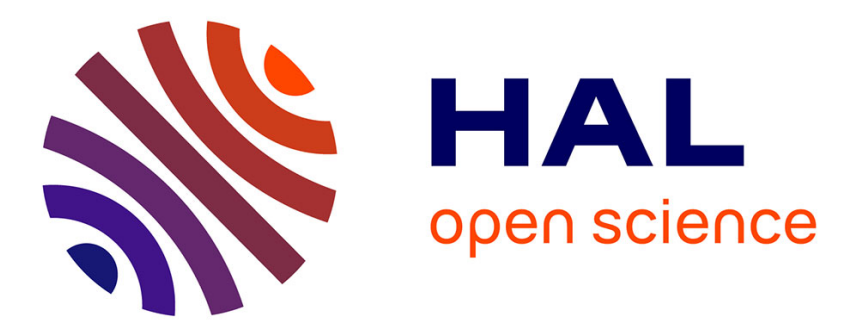

\title{
Comparison of Near-Real Time Estimates of Integrated Water Vapor Derived with GPS, Radiosondes, and Microwave Radiometer
}

\author{
Joël van Baelen, Jean-Pierre Aubagnac, Alain Dabas
}

\section{To cite this version:}

Joël van Baelen, Jean-Pierre Aubagnac, Alain Dabas. Comparison of Near-Real Time Estimates of Integrated Water Vapor Derived with GPS, Radiosondes, and Microwave Radiometer. Journal of Atmospheric and Oceanic Technology, 2005, 22, pp.201-210. 10.1175/JTECH-1697.1 . hal-01893817

\author{
HAL Id: hal-01893817 \\ https://hal.uca.fr/hal-01893817
}

Submitted on 11 Oct 2018

HAL is a multi-disciplinary open access archive for the deposit and dissemination of scientific research documents, whether they are published or not. The documents may come from teaching and research institutions in France or abroad, or from public or private research centers.
L'archive ouverte pluridisciplinaire HAL, est destinée au dépôt et à la diffusion de documents scientifiques de niveau recherche, publiés ou non, émanant des établissements d'enseignement et de recherche français ou étrangers, des laboratoires publics ou privés. 


\title{
Comparison of Near Real-Time Estimates of Integrated Water Vapor Derived with GPS, Radiosondes, and Microwave Radiometer.
}

\author{
Joël Van Baelen ${ }^{\mathbf{1}}$, Jean-Pierre Aubagnac ${ }^{1}$, and Alain Dabas ${ }^{1}$
}

1. Centre National de Recherches Météorologiques, CNRS - Météo-France, Toulouse, France

2. Now with: Laboratoire de Météorologie Physique, Observatoire de Physique du Globe de Clermont-Ferrand, CNRS - Université Blaise Pascal,

Clermont-Ferrand, France

\author{
Submitted: $\quad 10 / 02 / 2004$ \\ Final: $\quad 11 / 08 / 2004$ \\ Accepted: $\quad 24 / 08 / 2004$
}

\section{Corresponding author:}

Joël Van Baelen, Laboratoire de Météorologie Physique / Observatoire de Physique du Globe de Clermont-Ferrand, Université Blaise Pascal, 24 avenue des Landais, 63177 Aubière, France.

Tel : + $33-4-734073$ 94, Fax : + $33-4-73405136$

E-mail : joel.vanbaelen@opgc.univ-bpclermont.fr 


\begin{abstract}
In this study, we compare the integrated water vapor (IWV) retrieved with a global positioning system (GPS) receiver, radiosondes (RS) and a microwave radiometer (MWR) using data collected simultaneously during a three month campaign in the fall of 2002 in Toulouse, France. In particular for this study, the GPS analysis was performed in near real-time to provide estimates of the IWV in order to evaluate the potential of GPS observations for operational meteorological purpose. Although the three instrument estimates agree quite well together, the IWV estimates retrieved by GPS are generally larger than those of RS while we show evidence of a marked diurnal cycle: the differences are larger during the day (up to $2 \mathrm{~mm}$ ) than at night (less than $0.5 \mathrm{~mm}$ ). This can be explained by a daytime dry bias of the RS. Regarding the MWR, similar findings but to a lesser extent (differences between 0 and $1 \mathrm{~mm}$ ) are reported. Furthermore, we have established that the GPS estimates exhibit a strong dependency upon the IWV values resulting in a $15 \%$ faster variation when compared to the other means of IWV estmation in this study.
\end{abstract}




\section{1/ Introduction}

Water vapor is an important component of the atmosphere. The physics, dynamics and thermodynamics of many atmospheric processes are significantly influenced by water vapor distribution. That is the case for radiation transfer, energy balance, cloud formation and composition, convective initiation and convection development, precipitation systems. Likewise, water vapor distribution in the atmosphere displays a very variable spatial distribution and a quickly changing time scale. It is also a physical parameter of the atmosphere still difficult to measure with adequate spatial and time resolution under all weather conditions. Thus, the development of new techniques to measure atmospheric water vapor will be crucial for the advance of atmospheric sciences (Dabberdt and Schlatter, 1996).

Over the last decade, much work has been done to demonstrate the capability of the Global Positioning System (GPS) to derive atmospheric integrated water vapor (IWV) (Bevis et al . 1992, 1994; Businger et al, 1996; Duan et al., 1996; Tregoning et al., 1998; Wolfe and Gutman, 2000). Despite the fact that the GPS measurement do not provide humidity profiles, obvious advantages of that technique are that it can achieve good temporal resolution (less than one hour, down to 15 minutes), can be operated in all weather conditions, and can be run in an unattended manner. Furthermore, one could make use of the many GPS systems already deployed for geodetic purposes and complement the existing networks to offer a more homogeneous spatial distribution. However, for operational meteorology, it is important that the data be available in near realtime. In the United States of America and in Europe, recent developments have addressed this concern: for example, the COST-716 Near real time campaign (http://www.knmi.nl/samenw/cost716) and the NOAA GPS meteorology initiative (http://gpsmet.fsl.noaa.gov/jsp; Wolfe and Gutman, 2000). 
The objective of the present work is to make use of a multi-instrumented campaign carried out at the Centre National de Recherches Météorologiques (CNRM) in Fall 2002 in order to compare the integrated water vapor (IWV) retrieved in near real-time from GPS data with the IWV derived from radiosondes (RS) and microwave radiometer (MWR), and to investigate and eventually mitigate the possible sources of discrepancies in order to prepare for future operational use of GPS data at Météo-France. In section 2, we will present the campaign, while in section 3, we will describe the data acquired and the IWV estimation methods with the various techniques. In section 4, we will show how these techniques compare and we will discuss our findings, then we will address our concluding remarks in section 5 .

\section{2/ The measurement campaign}

On May $4^{\text {th }} 2002$, NASA launched the Earth Observing Satellite EOS-AQUA. On board this satellite, the Atmospheric Infra-Red Sounder (AIRS) is a radiometer designed to measure the infra-red radiation of the earth $(3.7$ to $15.4 \mu \mathrm{m})$ with very fine details due to its enhanced spatial and spectral resolution (a swath of about 14 $\mathrm{km}$ and 2378 spectral channels) (see http://www-airs.jpl.nasa.gov for more information). One of its most important application for meteorology is the restitution of water vapor profiles with an accuracy of better than $10 \%$ and a vertical resolution of better than1 kilometer. As this instrument foreshadows the future European Infrared Atmospheric Sounding Instrument (IASI) to be launched on board the Metop satellite in 2005 (for more details, see the following website http://www.esa.int/export/esaME/iasi.html), EUMETSAT has decided to participate in the validation process of AIRS. In France, CNRM has been selected as a validation experimental site to carry out a three month measurement campaign in order to provide calibration parameters for this instrument.

The campaign took place at the CNRM experimental grounds in Toulouse, France, from August 19 to November 19, 2002. It included the operation of two RS 
benches, a surface station providing pressure, temperature, humidity, precipitation rates, and up and down-welling visible and infrared radiation, two laser ceilometers, and a GPS station from the "Réseau GPS Permanent" (RGP) of the Institut Géographique National (IGN, //lareg.ensg.ign.fr/RGP/) installed at CNRM (station code TLMF). In addition, a commercial microwave radiometer owned and operated by the Office National d'Etude et de Recherche Aeronautique (ONERA) provided data for a one month period from August 22 to September 24.

Two satellite overpasses occurred daily during the AIRS campaign, one in each of the two time slots: 00-03 UTC and 11-14 UTC. Given that the local time is UTC $+2 \mathrm{~h}$ up to October 26 (summer daylight saving time) and UTC $+1 \mathrm{~h}$ afterwards, the 00-03 UTC time slot is representative of night-time conditions while the 11-14 UTC time slot corresponds to daytime conditions associated with the full development of the boundary layer. For each passage, two RS were released: the first one 1 hour and the second one 5 minutes before the time of closest proximity of the satellite to the experimental compound. The RS used are Vaisala RS-90-AG type, the tracking and data acquisition benches are DIGICORA MW-11 type and the balloons were inflated in order to get an approximate ascension rate of $5 \mathrm{~ms}^{-1}$ such that the nominal maximum altitude of around 27 kilometers was reached after about one and a half hour. Data from the RS were recorded at one second intervals during the entire ascents, starting at launch and extending up to balloon burst.

All the surface meteorological instruments deployed for the campaign recorded data on a continuous basis during the entire campaign, providing surface meteorological parameter measurements.

The GPS data used here are the hourly mean zenith total delays (ZTD) routinely produced by IGN in near real time: $Z_{T D} D_{\text {IGN }}$ The ZTD can be viewed as a synthetic parameter which includes all atmospheric contributions affecting the propagation of the electromagnetic waves from the satellites to the receivers, projected to the zenith through a mapping function. The GPS receiver is a LEICA RS500 system and the antenna is a Dorne-Margollin choke-ring antenna. The GPS 
raw data are acquired every second and stored for a full hour before being transmitted to the IGN for processing. Processing of the data of all the RGP GPS systems plus those of selected reference sites in Europe is done using the Bernese software (Hugentobler et al., 2001) under a network least square estimation approach. The International GPS Service ultra rapid orbit predicted parameters are used for orbits determination and time correction in conjunction with International Terrestrial Reference Frame (ITRF 2000) reference site positions. A cut-off angle of $10^{\circ}$, no a-priori tropospheric model and dry-Niell mapping functions are also used in order to calculate near real-time precise positioning of the stations as well as an estimate of the ZTD every hour (60 minute sampling). For each hourly calculation, times series of data lasting only the last three hours of observations are used in order to quicken the processing run times. The ZTD estimates, which correspond to hourly mean estimates at the GPS stations, are then transmitted to CNRM. The mean latency of those estimates is less than 1.5 after completion of the measurements.

The MWR is a commercially available 12 channel (20 to $60 \mathrm{GHz}$ ) WP3000 system from Radiometrics (//www.radiometrics.com/). The instrument observes brightness temperatures in regions of the microwave spectrum dominated by emission from water vapor (5 frequencies in the 22 to $30 \mathrm{GHz}$ domain) and molecular oxygen (7 frequencies in the 51 to $59 \mathrm{GHz}$ domain). The $22-30 \mathrm{GHz}$ MWR channels are calibrated by automated tipping and is specified at $0.5 \mathrm{~K}$. Such calibration using 6 pre-set elevation angles was routinely performed once a day right after mid-night during the entire campaign. The 51-59 GHz MWR channels are calibrated using a liquid nitrogen target with a specified accuracy of $0.5 \mathrm{~K}$. such calibration is considered stable for extended periods of time up to 6 months. The instrument provided 7.5-minute profiles of temperature and humidity up to 10 kilometers, as well as integrated water vapor and liquid water contents. The physical variables estimated by the MWR are computed by inversion of the radiances measured in the different channels through a neural network application. Training of the neural network consists in optimising its parameters such that inverted radiances match input profiles provided in a learning data set determined 
from real RS measurements. In this case, the MWR has been trained using radiative transfer equation (Schroeder and Westwater, 1991) forward modeling of 10 years of historical operational radiosondings from the synoptic station at Bordeaux-Merignac about $200 \mathrm{~km}$ west of Toulouse. Further technical details concerning the radiometer, the spectroscopic assumptions (line strength, width, etc.) and retrieval algorithms are provided in Ware et al. (2003), Ware et al. (2004) and Liljegren (2004).

\section{3/ IWV estimates}

In this paper, three estimates of the Integrated Water Vapor content (IWV) are compared: IWV $\mathrm{GPS}_{\mathrm{GS}}$ obtained from the ZTD derived from the raw GPS signal, $\mathrm{IWV}_{\mathrm{RS}}$ integrated from the RS data, and IWV $\mathrm{VWW}_{\mathrm{MW}}$ measured by the MWR.

$\mathrm{IWV}_{\mathrm{GPS}}$ :

The integrated water vapor content is defined by:

$$
I W V=\frac{1}{\rho_{l}} \int_{H}^{+\infty} \rho_{w}(z) d z
$$

where $\rho_{1}\left[\mathrm{kgm}^{-3}\right]$ is the density of liquid water, $\rho_{\mathrm{w}}(\mathrm{z})\left[\mathrm{kgm}^{-3}\right]$ is the density of water vapor as a function of altitude, and $\mathrm{H}$ is the altitude of the receiver. Thus, IWV is the height of water obtained if all the vapor contained in a vertical atmospheric column were condensed and brought to the receiver's pressure level.

Following Bevis et al (1992), the IWV $\mathrm{GPS}_{\mathrm{GP}}$ are derived from the ZTD defined as:

$$
Z T D=\int_{H}^{+\infty}(n(z)-1) d z=10^{-6} \int_{H}^{+\infty} N(z) d z
$$

where $\mathrm{n}(\mathrm{z})$ is the atmospheric refractive index and $\mathrm{N}(\mathrm{z})$ the atmospheric refractivity as function of the altitude $\mathrm{z}$ of the atmospheric parcel. ZTD is the sum of two atmospheric delays: the Zenith Hydrostatic Delay (ZHD) and the Zenith Wet Delay (ZWD):

$$
Z T D=Z H D+Z W D
$$


The first can be estimated from the mean surface pressure with good accuracy (Saastamoinen, 1972; Askne and Nordius, 1987) by:

$$
Z H D=2.276810^{-3} P_{S} /\left(1-2.6610^{-3} \cos (2 \Phi)-2.810^{-7} H\right)
$$

where $\Phi[\mathrm{rad}]$ is the latitude, $\mathrm{H}[\mathrm{m}]$ is the altitude, $\mathrm{P}_{\mathrm{s}}[\mathrm{hPa}]$ is the surface pressure, hence ZHD is expressed in [m]. The second is related to IWV via factor $\kappa$ (Askne and Nordius, 1987):

$$
\begin{gathered}
I W W=Z W D / \kappa \\
\kappa=461.5110^{-5}\left(3.71910^{5} / T_{m}+16.4221\right)
\end{gathered}
$$

$\mathrm{T}_{\mathrm{m}}[\mathrm{K}]$ is the mean of the column's water vapor temperature defined as (Davis et al, 1985):

$$
T_{m}=\int_{H}^{+\infty} e(z) / T(z) d z / \int_{H}^{+\infty} e(z) / T^{2}(z) d z
$$

where $\mathrm{e}(\mathrm{z})$ is the water vapor partial pressure and $\mathrm{T}(\mathrm{z})$ the temperature. $\mathrm{T}_{\mathrm{m}}$ can be approximated (Bevis et al., 1992) by :

$$
T_{m G P S}=70.2+0.72 \overline{T_{s}}
$$

where $\overline{T_{s}}$ is the hourly mean surface temperature.

It is to be noted that (8) is an empirical formula derived from a statistical analysis of RS results over the United States (Bevis et al., 1992). Thus, it is an approximate formula that is geographically and climatologically dependent. Hence, its uncertainty can affect the derivation of $\kappa(6)$ although we will see in the following that it does not seem to account for a noticeable bias.

To obtain $\mathrm{IWV}_{\mathrm{GPS}}$, ZHD is first estimated from the hourly mean surface pressure (corrected to account for the GPS receiver height: $14 \mathrm{~m}$ above ground) and $\mathrm{T}_{\mathrm{mGPS}}$ from the hourly mean surface temperature. Then, ZTD $_{\text {IGN }}$ and ZHD yield ZWD, and ZWD and $\kappa$ yield IWV. This procedure is summarized by the flow chart of Figure 1a. A few $\mathrm{ZTD}_{\mathrm{IGN}}$ were discarded according to the quality control parameter provided by IGN indicating that they corresponded to an unstable solution. 
IWV RS :

Refractivity $\mathrm{N}$ can be expanded in equation (2) to give:

$$
\begin{aligned}
& Z T D=10^{-6} {\left[77.62 \int_{H}^{+\infty}(p(z)-e(z)) / T(z) d z+\right.} \\
& 64.7 \int_{H}^{+\infty} e(z) / T(z) d z+ \\
&\left.3.71910^{5} \int_{H}^{+\infty} e(z) / T^{2}(z) d z\right]
\end{aligned}
$$

where $\mathrm{p}(\mathrm{z})$ is the total pressure in $[\mathrm{hPa}], \mathrm{e}(\mathrm{z})$ in $[\mathrm{hPa}], \mathrm{T}(\mathrm{z})$ in $[\mathrm{K}]$ and ZTD in $[\mathrm{m}]$ (Vaisala, 1986).

The definition of IWV can be developed into:

$$
I W V=2.166910^{-4} \int_{H}^{+\infty} e(z) / T(z) d z
$$

with $\mathrm{e}(\mathrm{z})$ in $[\mathrm{hPa}]$ and $\mathrm{T}(\mathrm{z})$ and IWV in [m]. Equations (7), (9) and (10) are numerically integrated once the vertical profiles of pressure, temperature and humidity given by the RS are interpolated to a regular vertical grid. The three estimates $T_{m R S}, I W V_{R S}$ and $Z_{T D} D_{R S}$ yield in turn $\kappa_{R S}, Z W D_{R S}$ and $Z_{H} H D_{R S}$ using equations (6), (5), and (3), respectively. Figure $1 \mathrm{~b}$ provides the flow chart corresponding to this procedure.

For the sake of comparison, the IWV estimates need to share the same altitude range. The integration of the GPS estimates served as our reference. To match the lower limit: the altitude of the GPS receiver, the contribution of the first 14 meters is removed from the RS integrated parameters. As for the upper limit, the statistical study of the campaign RS reaching $25 \mathrm{~km}$ teaches us that more than $99 \%$ of the total $I W V_{R S}$ is due to the first $10 \mathrm{~km}$. As a consequence, only soundings reaching at least $10 \mathrm{~km}$ are considered in the following, and their IWV $V_{\mathrm{RS}}$ is considered complete. On the contrary for ZHD (and therefore ZTD), the contribution of altitudes above $10 \mathrm{~km}$ is important and can reach one fourth of the total value. This contribution is therefore estimated by applying Equation (4) to the top of the radio sounding (Boccolari, 2001). In addition to soundings terminating early, a few more were discarded for having a defective temperature sensor. 
IWV

During its period of operation, ONERA's MWR produced every 7.5 minutes continuous vertical profiles of temperature, relative humidity, water vapor density and liquid water density extending up to $10 \mathrm{~km}$ as well as IWV and total liquid water. The IWV $\mathrm{V}_{\mathrm{MWR}}$ quoted below are hourly averages of the available MWR 7.5 minute IWVs. Excluded from the means are the observations flagged by the system as contaminated by rain. Again, when comparing radiometer with GPS, the contribution of altitudes lower than the GPS receiver is removed from IWV $\mathrm{VWR}_{\text {. }}$ However, when MWR and RS estimates are compared, the one meter altitude difference between the two instruments has been neglected given that the lateral separation that exist between them (about $7.5 \mathrm{~km}$ ) could be the source of more significant differences anyway.

\section{4/ Comparisons and discussion}

Using the formulations provided in the previous section to derive the IWV with the three different instruments, we will first consider the time series of IWV retrieved for the period of August 22 to September 24 when all three systems were operated. Although these formulas use SI units and express IWV in meters, it is common practice to use millimeters to represent the usual range of IWV values. Thus, millimeters will be used from now on in this paper when considering IWVs. As shown in Figure 2, the general impression delivered by the three instruments time series of derived IWV is that of an excellent agreement between the different estimates. Indeed, although the IWV values vary from about 10 to more than 40 millimeters in range over the entire month, all the large features of the variations are similarly rendered by the different estimates. In particular large and rapid transitions such as on Sept. 1, Sept. 2, and Sept. 16 are all in phase both in time and amplitude, while longer-term variations such as the slow diminution from Sept. 8 to Sept. 15 do also track very well. Nonetheless, the GPS estimate seems to display a more "noisy" (more variability and occasional spikes) time series than the microwave MWR. The RS estimates also depict reasonably well the general 
variation of IWV but cannot render the small time-scale features in between its sampling intervals. Examples of such small time-scale features with significant variations of more that $5 \mathrm{~mm}$ of IWV are noticeable between the September 2 night and mid-day sondes, between the September 3 noon and September 4 night sondes or between the September 9 noon and September 10 night sondes.

We will now address the more detailed comparisons between the IWV derived by pairs of the three instruments. Thus, we will focus on the August 22 to September 24 period when all three instruments were in operation. In order to perform the inter-comparisons on identical data sets (i.e., same number of measurement pairs under identical atmospheric conditions), we discarded all three instrument estimates at those times where one (or more) of them had been flagged as not valid. Only when appropriate, in order to complete the discussion, comparisons using extended data sets will be performed: the three months of GPS and RS data, and all the hourly estimates from GPS and microwave MWR.

In the following figures (Figures 3 through 5), the left panel shows the data distribution of the direct comparison of two IWV estimates, where circles indicate night-time data (00-03 UTC) and crosses indicate daytime data (11-14 UTC). The solid and dashed lines are the least square fit regression lines of unit slope for night-time and daytime data respectively. They indicate the corresponding mean bias between the two instrument estimates of IWV. Also drawn, a dotted line represents the linear regression (non unit slope plus intersect) for the entire data set and will be the object of a later discussion. For each time period, the right panels display the histogram of the difference between the two instrument estimates: night-time in the upper panel and daytime in the lower panel. If one accepts that the observed differences between the IWV measured with these various techniques are due to a constant bias plus random fluctuations, then these differences can be modelled by a Gaussian distribution defined by the sample mean and standard deviation of the measured differences considered. The modelled distribution is represented by the solid curve on top of the histograms, 
with the corresponding parameters on the right side of the panel box. However, given the sometimes small number of observations available, it is known that these parameters can be adversely influenced by occasional spurious data. Therefore, we have also defined a Gaussian representation that corresponds to the least square best fit to the histogram as depicted by the dashed curves on top of the histograms with the corresponding central and dispersion parameters indicated on the left side of the panel box. It is these more robust results that we will use in the following analyses and discussions, although we will still use the terms of "mean" value and "dispersion" of the results in the text. Finally, Figure 6 is also provided to graphically summarize the comparison results described in Figures 3, 4 and 5 such that the reader can glance at once the relative magnitude of the corresponding differences between the various instrument IWV estimates at night and at day. The arrows indicate the direction of the biases between pairs of instruments, while the biases with their sign are noted alongside the arrows and expressed in millimeters.

First, Figure 3 shows the comparison between the GPS and the RS estimates for the August 22 to September 24 period. Although most of the points seem reasonably aligned with similar values of IWV retrieved with both techniques, the separation between night-time and daytime data exhibits the most noteworthy feature: a better agreement at night than during day. Indeed, for the 00-03 UTC time window the mean difference is only about half a millimeter when it rises to close to 2 millimeters for the 11-14 UTC time window, with the GPS estimate being the wettest in both cases. As the uncertainty on the sample estimated mean values is less than $0.3 \mathrm{~mm}$, the comparison between the GPS and RS IWV difference at night and during day can be viewed as statistically significant. Indeed, the means of these two samples (night and day data) are significantly different to a confidence level in excess of 99 percent. The daytime bias noticed is further confirmed when the comparisons encompasses the entire campaign period from August 19 to November 19. In that case, the night-time difference is close to zero, while the daytime difference is still about 2 millimeters. 
To account for the contrasted behavior between GPS and RS, one could argue on the daytime dry bias of the RS as has been evidenced lately in the literature (Turner et al., 2003; Wang et al., 2002; Miloshevich et al., 2001; Westwater et al., 2003). This bias can be separated in two contributions, one due to the sondes material and aging (Wang et al., 2002) and one due to atmospheric radiation effects on the sonde sensors (Turner et al, 2003; Westwater et al., 2003, Wang et al., 2002). The latter is the dominant factor during daytime. Corrections have been proposed in the literature for different RS-80 types of sondes but none were applied in this study. Indeed, we have used RS-90-AG sonde models for which no statistical analysis currently exists, while no additional surface calibration procedure was performed at time of launch and the data acquisition package did not preserve the pre-launch data for later evaluation. Hence, we did not have the necessary information to perform any adequate correction. Likewise, the knowledge of the age of the sondes, all manufactured during May and June 2001, was of no use at this point as no statistical study has been performed to that effect on the RS-90 type of sonde and problems linked to aging were supposed to have been addressed by the manufacturer. Furthermore, besides the correction method developed at NCAR (Wang et al., 2002), another way to account for the sonde dry bias is to scale the corresponding profile such that the IWV derived from the RS matches a closely located MWR defined value (Liljegren et al., 1999; Revercomb et al., 2003; Turner et al., 2003; Westwater et al., 2003). Given that our present investigation goal is to compare different instruments including RS and MWR, such a correction was not performed either.

Hence, we will now compare the MWR and RS estimates of IWV for the period of August 22 to September 24 as shown on Figure 4. Here again the night-time comparison between the two estimates provides a better agreement than the daytime comparison: a mean difference of about 0.4 millimeter and 0.7 millimeter respectively with a statistical uncertainty of less than $0.2 \mathrm{~mm}$. Although those differences are smaller than those between GPS and RS for the same data set, they tend to confirm the sondes tendency for a dry daytime bias but one has to question 
its true amplitude. Indeed, the daytime difference of RS estimates with the GPS ones is much larger than the one with the MWR estimates. In particular, one can notice that from a similar difference with RS at night (respectively .5 and $.4 \mathrm{~mm}$ ), GPS and MWR estimates show contrasted behavior at day with respect to the RS estimates: a larger increase for GPS (plus $1.3 \mathrm{~mm}$ ) than MWR (plus .3 mm).

To investigate the relative behavior of GPS and MWR estimates, we will now consider Figure 5 which presents their comparison for the times of common data for the three instruments. It confirms that the difference between these two estimates is much larger at day than at night: $1.0 \mathrm{~mm}$ daytime but only $0.2 \mathrm{~mm}$ night-time, with a statistical uncertainty of about $0.3 \mathrm{~mm}$. However, if one computes the mean difference between the GPS and MWR IWV estimates using the 24 hours of daily data altogether instead of just the two satellite passage time slots, the resulting value is almost $0.0 \mathrm{~mm}(0.02 \mathrm{~mm})$ with a statistical uncertainty of less than $0.1 \mathrm{~mm}$. Thus, the GPS and MWR IWV estimates are equivalent with respect to their daily mean but exhibit discrepancies according to the time of day.

To better illustrate this latter point, Figure 7 shows the diurnal variation of the hourly averaged IWV derived with the three different instruments for the period of August 22 to September 24. This figure, which is also consistant with similar findings from another study conducted at the Lindenberg Observatory of the DWD (U. Leiterer, 2003, personal communication), calls for some comments. First, the very close agreement between the three different IWV estimates at night is confirmed, while the daytime values exhibit much stronger variability. Second, it is to be pointed out that the 11 UTC RS data point accounts only for a few soundings (4 out of 65) and should not be counted as representative. Third, the GPS mean hourly IWV estimate appears more variable from hour to hour than the MWR one.

Thus, Figure 7 further confirms that the mean $\mathrm{IWV}_{\mathrm{RS}}$ estimates exhibit a dry bias when compared to GPS and MWR IWV estimates. Furthermore, the MWR IWV estimates also show a slightly smaller mean hourly values throughout the day than 
at night when, on the average, more humidity would be expected due to surface evaporation. This could point to a possible slight dry bias of the MWR during daytime. If so, its cause is still a puzzle to us. First, we suspect the possible heating of the MWR and its environment from solar exposure given that calibration was performed at night and that the MWR calibration is sensitive to ambient temperature (T Hewison and C. Gaffard, Met. Office UK, personal communication). Second, the MWR training based on historical RS profiles could also explain part of the correlation between MWR and RS given the noticed daytime dry bias of the radiosondes used and the time of day for synoptic radiosonde launches. In contrast, no such diurnal dependency has been found at the ARM central facility using a two-channel radiometer (Revercomb et al., 2003). Finally, it is to be noted that the GPS mean hourly IWV estimates appear more variable from hour to hour than the MWR ones. The somewhat larger variability of the GPS estimates is also demonstrated if one looks at the dispersion of the IWV differences between pairs of instruments. Indeed, when GPS derived values are considered, the dispersion of the IWV difference with any of the RS or MWR estimate is about double that of the MWR - RS difference: around $2.5 \mathrm{~mm}$ instead of $1.3 \mathrm{~mm}$. This indicates that the GPS derived estimates present more fluctuations with respect to the other means of IWV measurements. To explain this, we can think of two origins. First, the heterogeneity of the atmospheric water vapor distribution encountered by the GPS signals as the satellites describe their arcs in the wide GPS system field of view. Second, the possible lack of stability of the ZTD estimates which are calculated in near real-time, thus, using relatively short time series to GPS processing standards as well as predicted orbits instead of precise orbit determinations. However, it is to be noted that no such noisy behavior of the GPS estimates has been reported in other studies such as those conducted at the ARM central facility (Revercomb et al., 2003). Therefore, we reckon that particular care should be given to the GPS processing performed in the future. 
Another way to look at the data is to separate the comparisons according to classes of IWV as it is done in Table 1 where the first column indicates the overall IWV estimate difference for the two instruments indicated (GPS-RS, and GPS-MWR, respectively) using all the data available throughout the campaign: the three months of GPS and RS data, and all of the hourly estimates from GPS and microwave MWR. The following columns show the corresponding differences when the GPS IWV estimate is either less than $15 \mathrm{~mm}$, comprised between 15 and $25 \mathrm{~mm}$, comprised between 25 and $35 \mathrm{~mm}$, or larger than $35 \mathrm{~mm}$. As indicated already earlier, the overall IWV estimate differences shown here do not truly account for the comparison between the two instruments involved respectively, as marked diurnal variations have been demonstrated. However, they are an indication of the "mean bias" between the two instruments. Hence, a similar remark will hold for the classified results: they indicate the mean difference for a category of IWV contents, but underlying diurnal variations are not resolved. The classified results reveal that the GPS IWV estimates, when compared to the two other instrument estimates, present a somewhat linear trend from a significant negative bias (i.e., a dry bias) in dry atmosphere conditions to very large positive bias (i.e., a wet bias) in atmospheric conditions with large humidity content. Although statistically less significant due to the much smaller number of data, the difference of IWV estimates from RS and MWR, not shown in the table, does not present any definite trend with respect to the IWV value. This finding was already depicted in Figures 3 to 5 where the dotted line on the left side panel represented the linear regression between the IWV estimates of each pair of instruments. There, it is obvious that the IWV $\mathrm{GPS}_{\mathrm{GPS}}$ varies faster than the two other IWV estimates, while the regression between IWV $\mathrm{V}_{\mathrm{RS}}$ and IWV $\mathrm{V}_{\mathrm{MWR}}$ is close to the unit slope lines. Indeed, using all the data available (corresponding to the data sets of Table 1, thus larger than those used for Figures 3 and 5), we computed the corresponding linear regressions:

$$
\begin{gathered}
\mathrm{IWV}_{\mathrm{RS}}=.869 \times \mathrm{IWV}_{\mathrm{GPS}}+2.06, \\
\mathrm{IWV}_{\mathrm{MWR}}=.819 \times \mathrm{IWV}_{\mathrm{GPS}}+4.60 \\
\mathrm{IWV}_{\mathrm{RS}}=1.04 \times \mathrm{IWV}_{\mathrm{MWR}}-1.65
\end{gathered}
$$


These equations confirm that the GPS estimates of IWV vary about $15 \%$ faster that the two other instruments (13\% compared to RS, $18 \%$ compared to MWR but the periods of comparison are not similar: 3 months twice a day for RS while only 1 month but $24 \mathrm{~h}$ a day for MWR), while the MWR estimates vary slightly less quickly than the RS, possibly due to the effect of the RS dry bias which is preponderant (if due to solar radiation) at times of lesser IWV. The $15 \%$ faster rate of change of IWV estimates with GPS is significantly large and has not been revealed in any other previous studies. The origin of such IWV dependy for the GPS estimates is being further investigated.

Finally, we can conclude that the GPS retrieval of IWV is IWV dependant. This finding corroborates reports of seasonal variations for similar comparisons involving GPS retrieval of IWV indicated in other studies, such as Liljegren et al. (1999). Thus, in such instances, the seasonal variation factor is actually linked to the corresponding humidity content of the atmosphere at a given season.

To further investigate if this behavior of the GPS IWV estimates is instrumental or linked to our calculations, we have compared the different terms of the various equations of section 3 estimated through the GPS procedure with direct estimations derived from RS profiles. Two possible sources of discrepancies are the use of the surface pressure and the mean surface temperature in order to derive the hydrostatic component (ZHD) and the wet componant (ZWD) to IWV conversion factor $\kappa$. First, it can be shown that the $T_{m}$ derivation has no significant influence on the $\kappa$ coefficient. Indeed, as shown in Figure 8, the $\mathrm{T}_{\mathrm{m}}$ comparison between the one integrated from the sonde profiles and the one estimated from the surface temperature reveals that, although somewhat different from the Bevis (1992) formulation both for daytime and night-time estimates, it is actually at night that the estimation is less accurate, when the resulting IWV values are in fact the closest. Second, we have found that both ZHD estimates, from the RS and using the Saastamoinen relationship given in equation (4), were very close. Hence, the ZWD differences that exist are solely due to ZTD differences. Therefore, one 
cannot rule out the fact of systematic dependence of GPS ZTD retrieval upon the actual atmospheric humidity content.

\section{5/ Concluding remarks}

We will now try to summarize our previous section findings concerning the estimation of IWV with GPS, RS and MWR.

First, based on a month long comparison, all three estimates have shown similar and in phase variations of IWV according to weather changes, while the higher time resolution achieved with GPS and MWR with regards to RS has demonstrated its ability to reveal short scale features. Thus, the near real time GPS estimation of IWV demonstrates its potential for operational use.

However, the GPS estimates have proven "noisier" than the two other means of derivation. We believe that this can be due to the in-homogeneity of the atmospheric water vapor in the wide GPS field of view, and to the near real time calculation lack of stability. We are currently considering ways to improve the later with our IGN partners.

Second, a detailed comparison of the different estimates has demonstrated a contrasting behavior between night and day. Although for both our periods of comparison (00 to 03 and 11 to 14 UTC from 22 of August to 24 of September, 2002) the GPS IWV estimate is the wettest and the RS one the driest, the differences between estimates are much larger at day than at night. Indeed, the difference varies from less than $0.5 \mathrm{~mm}$ at night up to $2 \mathrm{~mm}$ at day. Hence, we have put forth that the RS-90-AG exhibits a noticeable daytime dry bias which could be linked to our way of operating them and the corresponding lack of possible correction.

When comparing the GPS IWV estimates with the MWR values, a similar trend is noticeable but to a lesser extent with larger differences during the day (about 1 $\mathrm{mm}$ ) than at night (about $0.2 \mathrm{~mm}$ ). Therefore, this indicates also a potential dry 
bias of the MWR at day. We suspect two factors which can cause this bias: the sensitivity of the MWR to the ambient temperature with respect to calibration of the brightness temperature and the training of the system with historical radiosondings which include an inherent dry bias in their measurements.

Finally, we have also shown that the GPS IWV estimates were dependent on the IWV itself, and we have tracked this correlation back to the ZTD determination itself and not to the derivation equations. In order to investigate the possibility that this might be due to the near real time determination of the GPS parameters, we plan to perform comparisons with estimates derived from post-processed GPS analyses, using precise orbit and longer session windows.

As the motivation for this campaign was the provision of data to help validate the AIRS instrument on board the EOS AQUA satellite, it is satisfactory to note that the estimates of IWV with the different instruments and their corresponding accuracy have been accepted by Eumetsat as meeting their requirements. However, one must keep in mind also that in the first stage of validation and calibration of the retrieval algorithms for AIRS, the humidity and temperature profiles from the sondes are the products of primary interest more than the IWV. 


\section{Acknowledgments}

The authors want to thank M-E. Gimonet from ONERA for operating and providing the data of the microwave MWR, Th. Duquesnoy and B. Garayt from IGN/RGP for their support with the GPS system and the timely delivery of the ZTDs during the campaign, and the CNRM/GMEI/4M staff for their dedicated work to operate the RS stations and service the instruments during the campaign. The authors also want to acknowledge the three anonymous reviewers for their careful, precise and constructive review. They have largely contributed to the improvement of this article.

This work has been performed under the EUMETSAT contract EUM/CO/01/893/PS through the Centre National d'Etudes Spatiales (CNES). 


\section{References}

Askne J., and H. Nordius, 1987, "Estimation of tropospheric delay for microwaves from surface weather data”. Radio Science, vol. 22, pp. 379-386.

Bevis M., S. Businger, T. A. Herring, C. Rocken, R. A. Anthes, and R. H. Ware, 1992, "GPS Meteorology: Remote sensing of atmospheric water vapor using the Global Positioning System”, Journal Geophys. Res., vol 103, pp. 15787-15801.

Bevis M., S. Businger, S. Chiswell, T. A. Herring, R. A. Anthes, C. Rocken, and R. H. Ware, 1994, “GPS Meteorology: Mapping zenith wet delay onto precipitable water", Journal of Applied Meteorology, vol 33, pp. 379-386.

Boccolari M., S. Fazlagic, P. Frontero, L. Lombroso, S. Pugnaghi, R. Santangelo, S. Corradini, S. Teggi, 2001, "Comparison between ZTD delays obtained by radiosounding data and ZTD obtained by GPS data", EGS Gen. Assembly, Nice.

Businger S., S.R. Chiswell, M. Bevis, J. Duan, R.A. Anthes, C. Rocken, R.H. Ware, M. Exner, T. VanHove, and F. Solheim, 1996, "The promise of GPS in atmospheric monitoring”. Bull. Amer. Meteor. Soc., vol. 77, pp. 5-18.

Dabberdt W., and T.W. Schlatter, 1996, "Research opportunities from emerging atmospheric observing and modeling capabilities: Report of the Second Prospectus Development Team of the U.S. Weather Research Program". Bull. Amer. Meteor. Soc., vol. 77, pp. 305-323.

Davis, J., T. Herring, I. Shapiro, A. Rogers, and G. Elgered, 1985, “Geodesy by radio interferometry: Effects of atmospheric modeling errors on estimates of baseline length", Radio Sci., vol 20, pp 1593-1607.

Duan J. M. Bevis, P. Fang, Y. Bock, S. Chiswell, S. businger, C. Rocken , F. Solheim, T. VanHove, R. Ware, S. McClusky, T.A. Herring, and R.W. King, 1996, "GPS meteorology: direct estimation of the absolute value of precipitable water", J. Appl. Meteor., vol 35, pp. 830-838. 
Hugentobler U., S. Schaer, and P. Fridez, 2001, "Bernese GPS software version 4.2”. Astronomy Institute, University of Bern, Bern, Switzerland.

Liljegren J.C., B.M. Lesht, T. VanHove, and C. Rocken,1999, “A comparison of integrated water vapor from microwave radiometer, balloon-borne sounding system, and global positionnng system", Ninth ARM Science Team Meeting, San Antonio, TX, March 22-26, 1999.

Liljegren J.C., 2004, "Improved retrievals of temperature and water vapor profiles with a twelve-channel radiometer", Eight Symposium on Integrated Observing and Assimilation Systems for Atmosphere, Oceans, and Land Surface, Seattle, WA, Amer. Meteor. Soc.

Miloshevich L., H. Vömel, A. Paukkunen, A.J. Heymsfield, and S.J. Oltmans, 2001, "Characterization and correction of relative humidity measurements from Vaïsala RS80-A radiosondes at cold temperatures", Journal of Atmospheric and Oceanic Technology, vol 18, pp. 135-156.

Revercomb H.E., D.D. Turner, D.C. Tobin, R.O. Knuteson, W.F. Feltz, J. Barnard, J. Bösenberg, S. Clough, D. Cook, R. Ferrare, J. Goldsmith, S. Gutman, R. Halthore, B. Lesht, J. Liljegren, H. Linné, J. Michalsky, V. Morris, W. Porch, S. Richardson, B. Shmid, M. Splitt, T. VanHove, E.Westwater, and D. Whiteman, 2003, “The ARM program's water vapor intensive observation periods : overview, initial accomplishments, and future challenges”, Bull. Amer. Meteor. Soc., vol 84, pp. 217-236.

Saastamoinen J., 1972, "Atmospheric correction for the troposphere and stratosphere in ranging satellites", in The use of Artificial Satellites for Geodesy, Geophys. Monogr. Ser., vol. 15, edited by S. W. Henriksen et al., pp. 247-251, AGU, Washington, D. C.

Tregoning P., R. Boers, D. O’Brien, and M. Hendy, 1998, “Accuracy of absolute precipitable water vapor estimates from GPS observations", J. Geophys. Res., vol 103, pp. 28701-28710. 
Turner D. D., B. M. Lesht, S. A. Clough, J. C. Liljegren, H. E. Revercomb, D. C. Tobin, 2003, "Dry bias and variability in Vaisala RS80-H radiosondes: the ARM experience", Journal of Atmospheric and Oceanic Technology, vol 20, pp. 117132.

Vaisala Oy, "METPAR: Post ascent analysis program", 1986, COREX Program System, information notice R0465-1.

Wang J., H.L. Cole, D.J. Carlson, E.R. Miller, and K. Beierle, 2002, “Corrections of humidity measurement errors from the Vaïsala RS80 Radiosonde - application to TOGA-COARE data", Journal of Atmospheric and Oceanic Technology, vol 19, pp. 981-1002.

Ware R., R. Carpenter, J. Güldner, J. Liljegren, F. Solheim, and F. Vandenberghe, 2003, "A multi-channel radiometric profiler of temperature, humidity and cloud liquid", Radio Sci., 38, 8079-8091.

Ware R., P. Herzegh, F. Vandenberg, J. Vivekanandan, and E. Westwater, 2004, "Ground-based radiometric profiling during dynamic weather conditions", to appear in Journal of Applied Meteorology.

Westwater E.R., B.B. Stankov, D. Cimini, Y. Han, J.A. Show, B.M. Lesht, and C.N. Long, 2003, "Radiosonde humidity soundings and microwave radiometers during Nauru99”, Journal of Atmospheric and Oceanic Technology, vol 20, pp. 953-971.

Wolfe D.E., and S.I. Gutman, 2000, "Developing an operational surface-based GPS water vapor observing system for NOAA: Network design and results", Journal of Atmospheric and Oceanic Technology, vol 17, pp. 426-440. 


\section{Captions for Tables and Figures:}

Table 1: Repartition of IWV differences given in millimeters between GPS, RS, and MWR according to IWV classes also expressed in millimeters. All data available have been used: $(*)$ all three months of campaign for RS and GPS, (**) all hourly data of the 22 Aug. to 24 Sept. period for MWR and GPS.

Figure 1: Flow charts of a) the GPS IWV estimate calculation, b) the RS IWV calculation.

Figure 2: Time series of the IWV estimates retrieved with GPS (gray dashes), RS (crosses), and MWR (continuous black line) for the period August 22 to September 24, 2002.

Figure 3: Comparison between IWV estimates obtained with GPS (IWV ${ }_{\mathrm{GPS}}$ ) and $\mathrm{RS}$ adjusted for the altitude difference (IWV $\mathrm{RS}_{\text {adj. }}$ ).

Figure 4: Comparison between IWV estimates obtained with MWR (IWV $\mathrm{MWR})$ and RS (IWV $\mathrm{RS})$.

Figure 5: Comparison between IWV estimates obtained with GPS (IWV $\mathrm{GPS}_{\text {) }}$ and MWR adjusted for the altitude difference (IWV ${ }_{\text {MWR adj.). }}$. 
Figure 6: Nighttime and daytime summary of IWV estimates comparisons between GPS, RS, and MWR for the period of August 22 to September 24, 2002. All values are expressed in millimeters. (*) Note: between brackets the IWV difference between GPS and RS using all three months of common data for the period of August 19 to November 19, 2002.

Figure 7: Diurnal variation of mean hourly IWV estimates obtained with GPS (circles), MWR (squares), and RS (triangles).

Figure 8: Comparison between $\mathrm{T}_{\mathrm{m}}$ derived from RS (circles and crosses) and $\mathrm{T}_{\mathrm{m}}$ estimated from surface temperature measurement using the relationship of equation (3) (bold straight line) as a function of the hourly mean surface temperature. 
Tables :

Overall

GPS - RS *

GPS - MWR **

0.9

0.0
$-1.4$

$-0.7$

0.8

1.3

0.1

2.4

Table 1: Repartition of IWV differences given in millimeters between GPS, RS, and MWR according to IWV classes also expressed in millimeters. All data available have been used: $\left(^{*}\right)$ all three months of campaign for RS and GPS, (**) all hourly data of the 22 Aug. to 24 Sept. period for MWR and GPS. 


\section{Figures :}

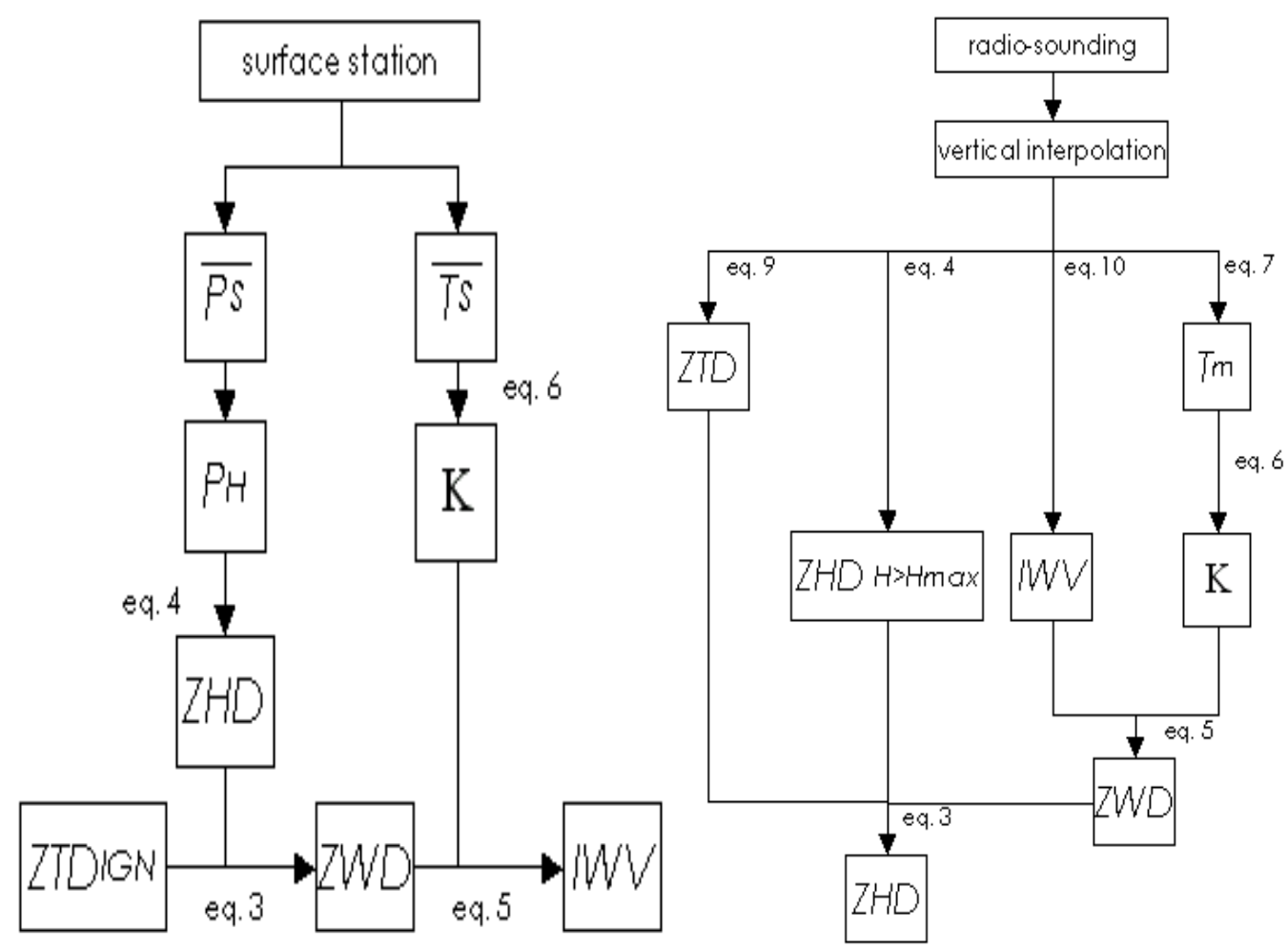

Figure 1: Flow charts of a) the GPS IWV calculation and b) the RS IWV estimate calculation.

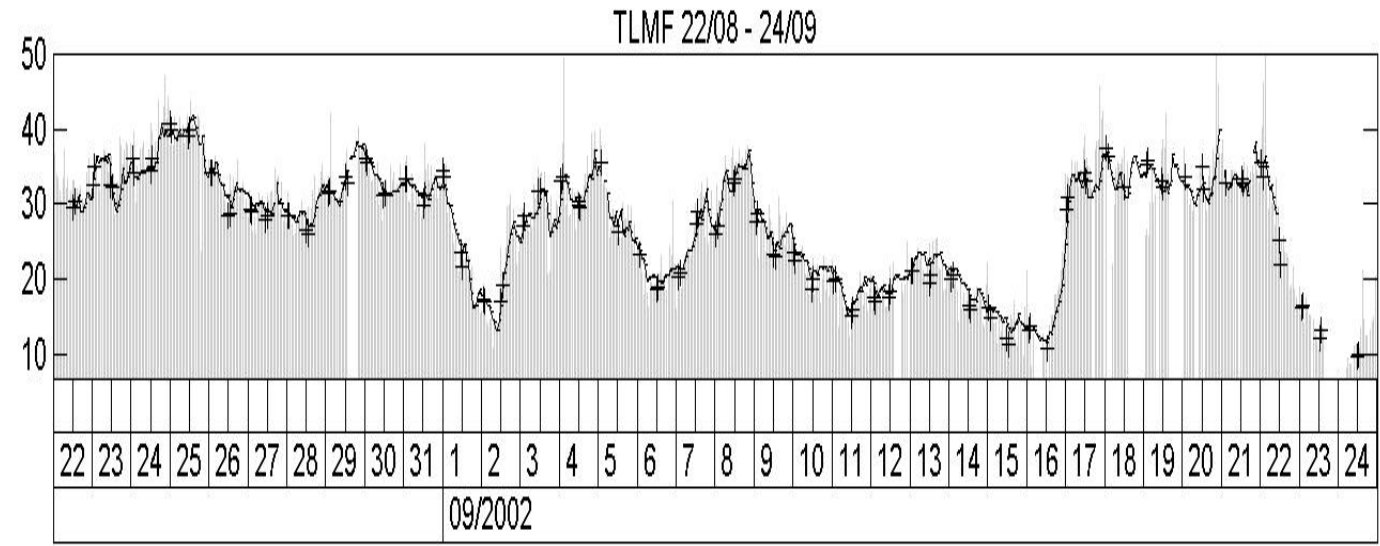

Figure 2: Time series of the IWV estimates retrieved with GPS (gray dashes), RS (crosses), and MWR (continuous black line) for the period August 22 to September 24, 2002. 

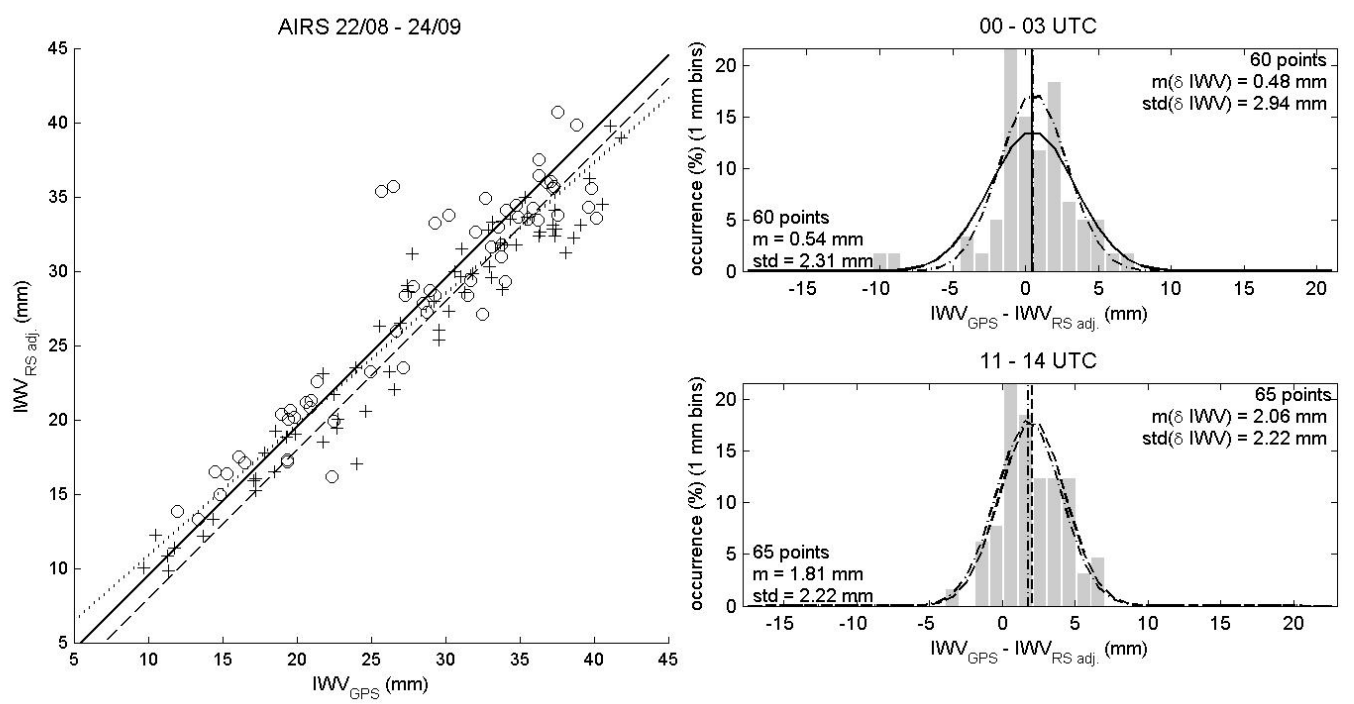

Figure 3: Comparison between IWV estimates obtained with GPS (IWV $\mathrm{GPS}_{\text {) }}$ and $\mathrm{RS}$ adjusted for the altitude difference (IWV $\mathrm{RS}$ adj.).
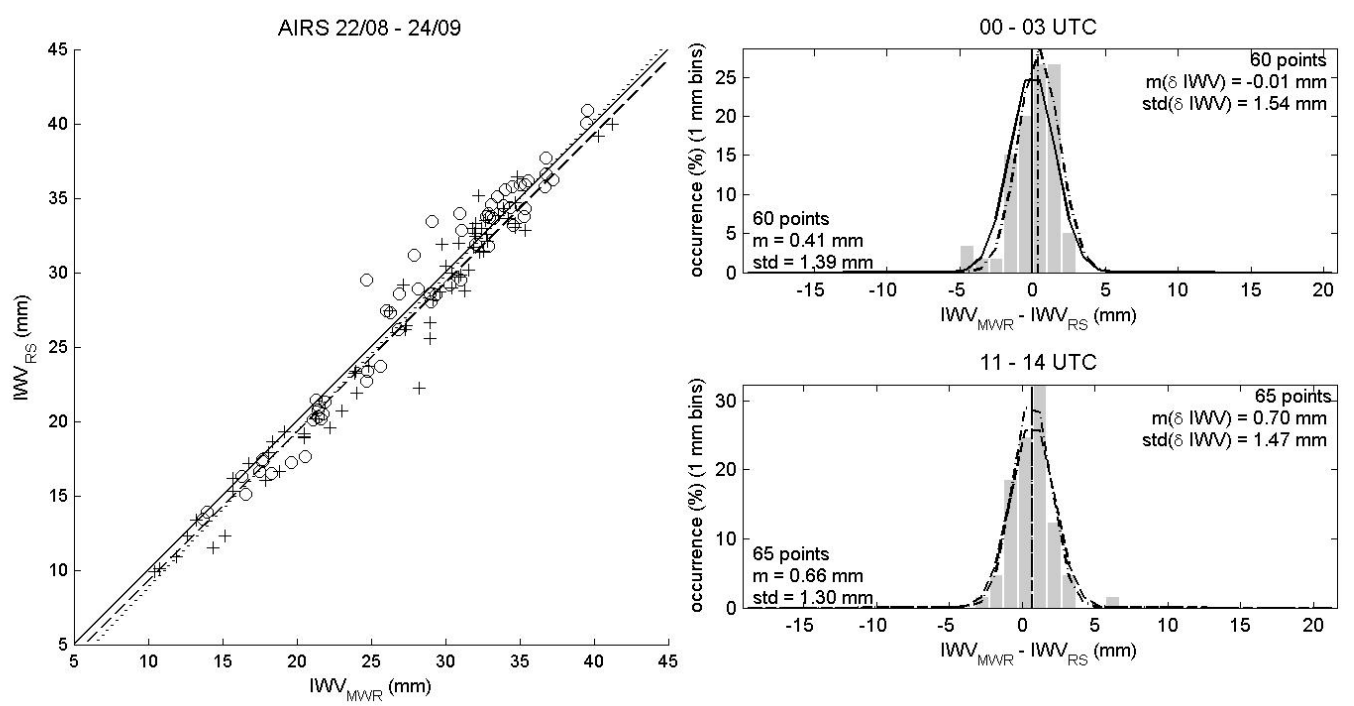

Figure 4: Comparison between IWV estimates obtained with MWR (IWV $\mathrm{MWR}_{\text {) }}$ and RS (IWV $\mathrm{RS})$. 

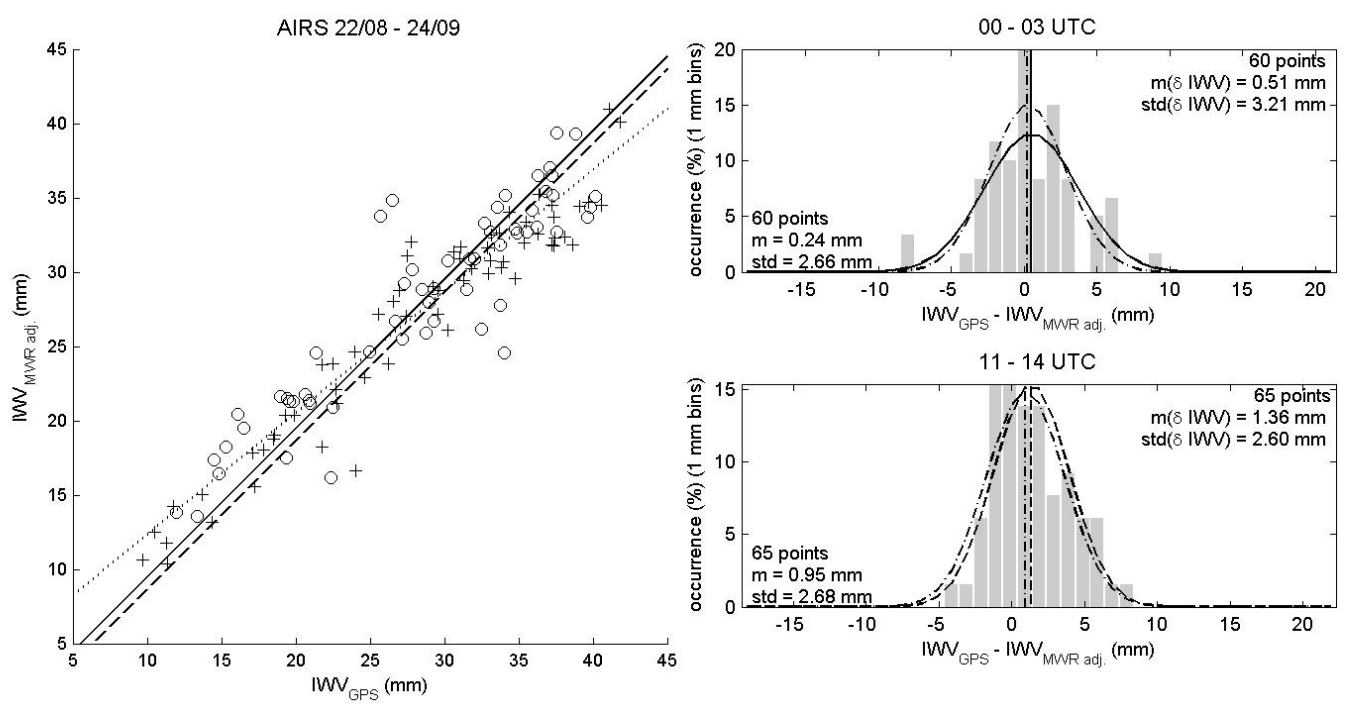

Figure 5: Comparison between IWV estimates obtained with GPS (IWV ${ }_{\text {GPS }}$ ) and MWR adjusted for the altitude difference (IWV MWR adj.).
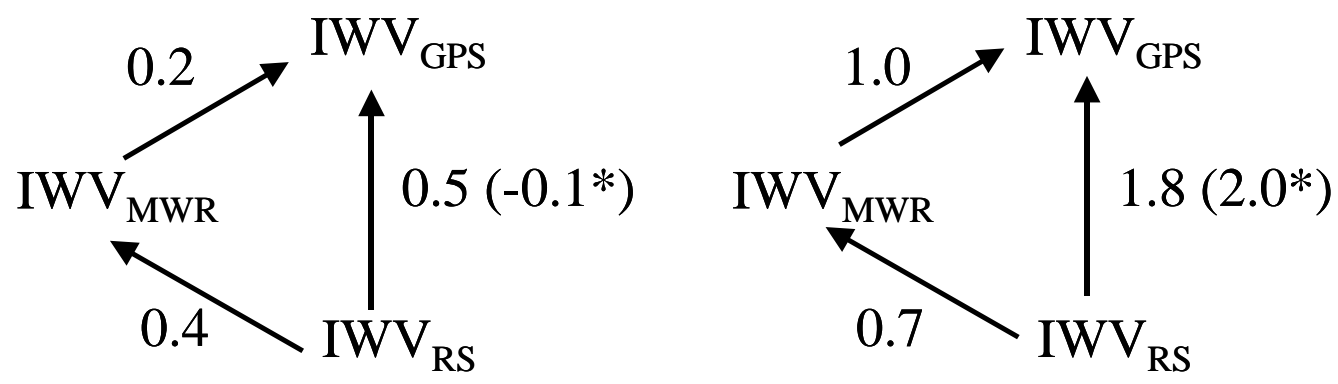

Figure 6: Nighttime and daytime summary of IWV estimates comparisons between GPS, RS, and MWR for the period of August 22 to September 24, 2002. (*)Note: between brackets the IWV difference between GPS and RS using all three months of common data for the period of August 19 to November 19, 2002. 


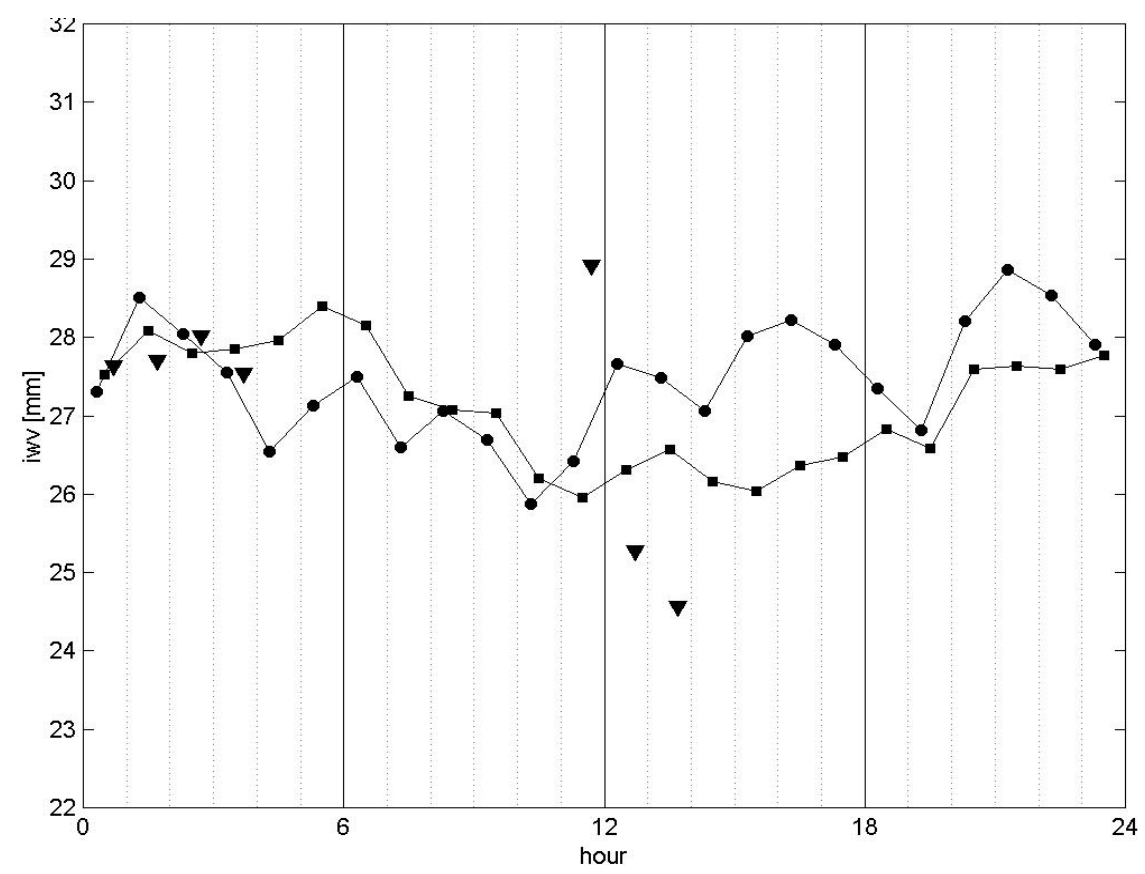

Figure 7: Diurnal variation of mean hourly IWV estimates obtained with GPS (circles), MWR (squares), and RS (triangles).

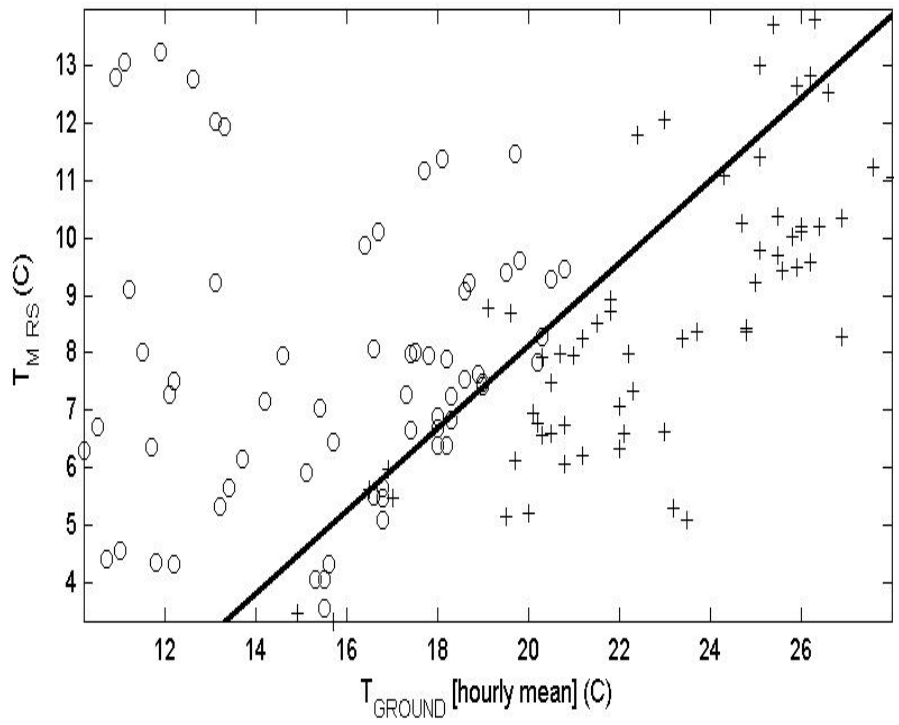

Figure 8: Comparison between $\mathrm{T}_{\mathrm{m}}$ derived from RS (circles and crosses) and $\mathrm{T}_{\mathrm{m}}$ estimated from surface temperature measurement using the relationship of equation (3) (bold straight line) as a function of the hourly mean surface temperature. 